
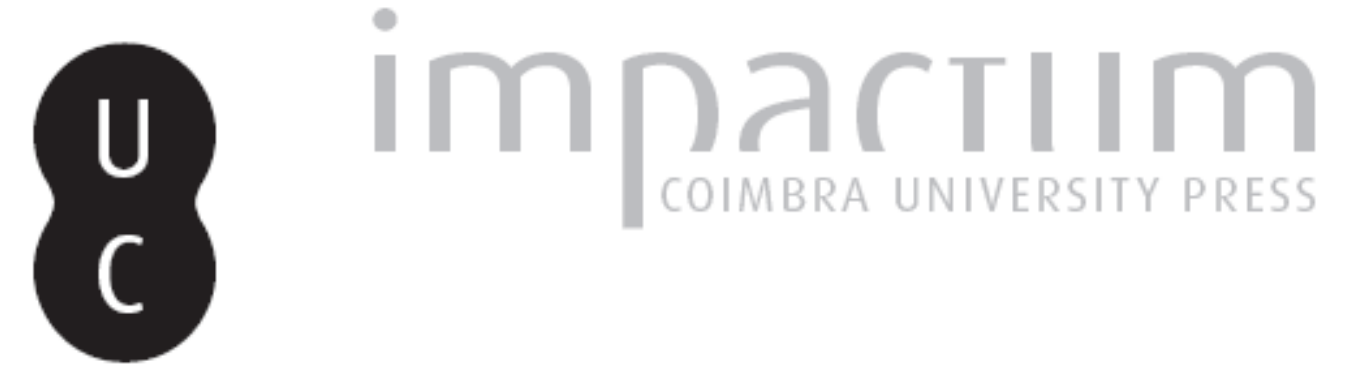

\title{
Vittorio Gregotti e Álvaro Siza: afinidades electivas entre dois arquitectos contemporâneos
}

Autor(es): $\quad$ Grande, Nuno

Publicado por: Imprensa da Universidade de Coimbra

URL persistente:

URI:http://hdl.handle.net/10316.2/44964

DOI:

DOI:https://doi.org/10.14195/0870-8584_12_1

Accessed : $\quad$ 26-Apr-2023 11:52:14

A navegação consulta e descarregamento dos títulos inseridos nas Bibliotecas Digitais UC Digitalis, UC Pombalina e UC Impactum, pressupõem a aceitação plena e sem reservas dos Termos e Condições de Uso destas Bibliotecas Digitais, disponíveis em https://digitalis.uc.pt/pt-pt/termos.

Conforme exposto nos referidos Termos e Condições de Uso, o descarregamento de títulos de acesso restrito requer uma licença válida de autorização devendo o utilizador aceder ao(s) documento(s) a partir de um endereço de IP da instituição detentora da supramencionada licença.

Ao utilizador é apenas permitido o descarregamento para uso pessoal, pelo que o emprego do(s) título(s) descarregado(s) para outro fim, designadamente comercial, carece de autorização do respetivo autor ou editor da obra.

Na medida em que todas as obras da UC Digitalis se encontram protegidas pelo Código do Direito de Autor e Direitos Conexos e demais legislação aplicável, toda a cópia, parcial ou total, deste documento, nos casos em que é legalmente admitida, deverá conter ou fazer-se acompanhar por este aviso.

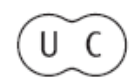




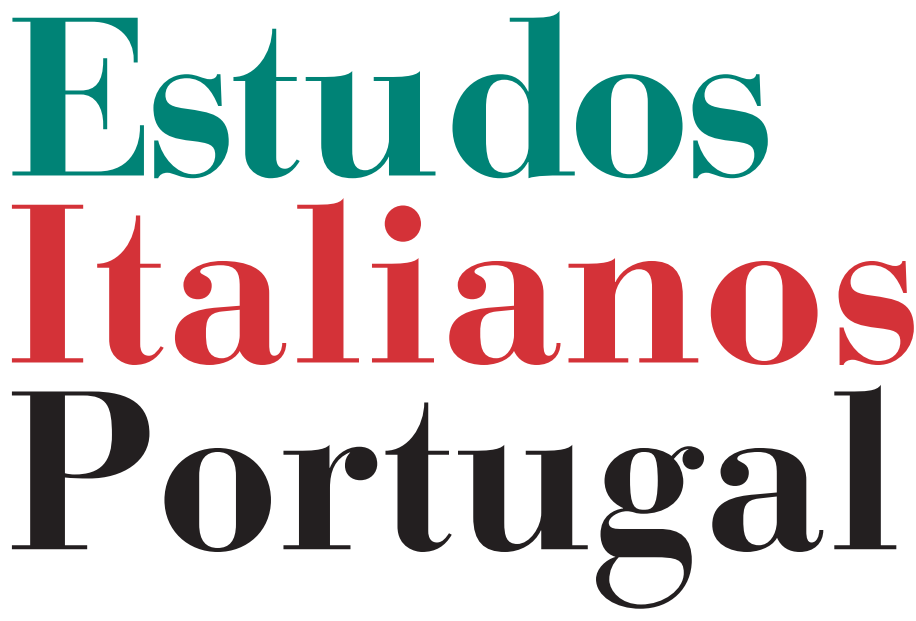

Instituto

Italiano

de Cultura

de Lisboa

Nova Série

No 12

2017 


\section{VITTORIO GREGOTTI E ÁLVARO SIZA. AFINIDADES ELECTIVAS ENTRE DOIS ARQUITECTOS CONTEMPORÂNEOS}

NunO GRANDE*

EXISTE UMA NATURAL AFINIDADE cultural entre a criação artística e arquitectónica dos diferentes países latinos europeus, legada, através dos tempos, por circunstâncias geográficas, históricas e culturais comuns, há muito identificadas. A herança civilizacional greco-romana e a ligação umbilical à cultura mediterrânica explicam, em grande parte, essa afinidade colectiva. Mas existem certamente outras razões, de índole mais pessoal, que terão levado criadores de diferentes regiōes do Sul da Europa a viajar e a estabelecer contactos permanentes com os seus congéneres latinos. Essas "afinidades electivas" - aproximando-nos aqui de uma dimensão mais íntima, ideológica ou ética do conceito, definida por Goethe na literatura, ou por Max Weber no campo sociológico -, dão suporte à cumplicidade conceptual que descrevemos neste texto, estabelecida entre dois arquitectos contemporâneos, o italiano Vittorio Gregotti (Novara, 1927) e o português

* Nuno Grande (Luanda, 1966). Arquitecto (FAUP, 1992) e Doutorado em Arquitectura pela UC (2009). Professor Auxiliar da UC, no Departamento de Arquitectura da Faculdade de Ciências e Tecnologia e no Colégio das Artes, sendo ainda Investigador do Centro de Estudos Sociais. Crítico e Curador de Arquitectura com obras publicadas e exposições realizadas em Portugal e no estrangeiro (Brasil, Espanha, França e Itália).ngrande@darq.uc.pt 
Álvaro Siza (Matosinhos, 1933), curiosamente iniciada num cruzamento comum com a cultura arquitectónica espanhola.

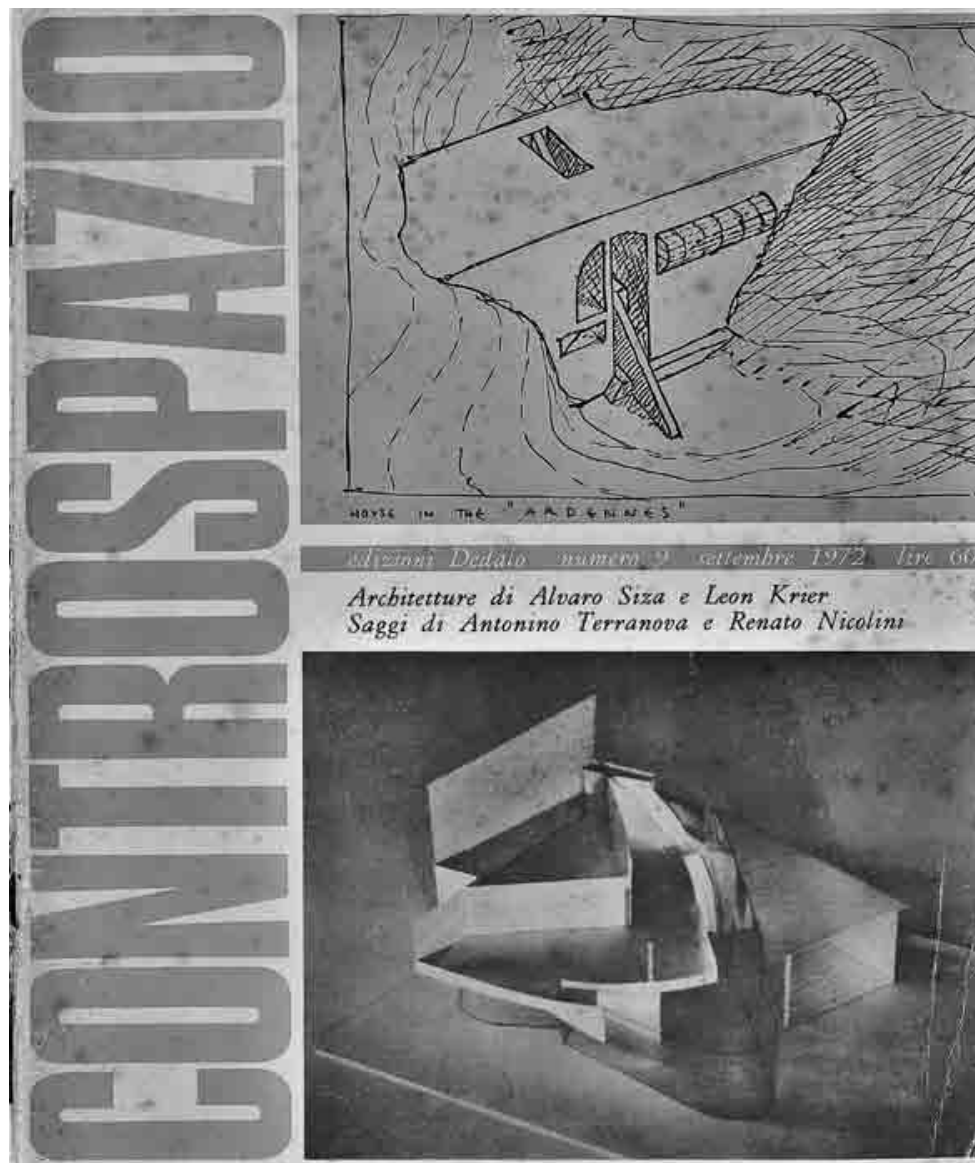

Fig. 1 Capa da Revista Controspazio, 9, 1972. Fonte: Arquivo Pessoal de Nuno Portas.

PRIMEIRA AFINIDADE: LEGADOS E VALORES CONCEPTUAIS

$\mathrm{Na}$ verdade, o primeiro encontro entre os dois criadores dáse no âmbito dos denominados "Pequenos Congressos" ibéricos - mais propriamente no Congresso de Vitória, no País 
Basco, em 1968 -, sendo então "apadrinhado" por dois dos mentores da iniciativa: os arquitectos Nuno Portas e Oriol Bohigas, editores, críticos de arquitectura e divulgadores seminais da obra de Siza no contexto português e espanhol.

Editor à época da revista portuguesa Arquitectura, Portas assinara, em 1967, um artigo no periódico espanhol Hogar y Arquitectura, n. ${ }^{\circ}$ 68, em torno do percurso dos jovens arquitectos portugueses, com especial destaque para Siza (então com 34 anos) ${ }^{1}$; a que se seguiria um artigo de Bohigas em 1968, no no 101 da revista Serra d'Or, sobre o modo como em Portugal os arquitectos lutavam então por conta própria ${ }^{2}$. Esse interesse mútuo justificou o convite ao jovem e tímido Álvaro Siza y Vieira (como seria apresentado) para participar no Pequeno Congresso de Vitória ${ }^{3}$, munido, entre outros, dos seus primeiros projectos para a sua cidade natal - a Casa de Chá da Boa Nova (1963) e a Piscina das Marés de Leça da Palmeira (1966).

Também convidado para a iniciativa, enquanto redactor da celebrada revista italiana Casabella, Vittorio Gregotti (então com 41 anos) reconhece de imediato na obra de Siza muitos dos valores e caminhos que vinha defendendo, sobretudo nesse polémico tempo de crise e de crítica da Arquitectura Moderna. Dois anos antes, Gregotti publicara um livro seminal para a cultura arquitectónica pós-funcionalista, Il territorio dell'architettura ${ }^{4}$, no qual defendia a necessidade de resgatar uma relação ancestral entre a arquitectura e o seu contexto físico e cultural, a partir de uma leitura crítica da antropização do território, evocando a longa tradição urbana

${ }^{1}$ Nuno Portas, "Sobre la joven generación de arquitectos portugueses", Hogar y Arquitectura, 68, 1967, pp. 77-84.

2 Oriol Bohigas, "A Portugal també els arquitects fan la guerra pel seu compte", Serra d'Or, 101, 1968, pp. 59-61.

${ }^{3}$ Nuno Correia, "A crítica arquitectónica, o debate social e a participação portuguesa nos 'Pequenos Congressos' - 1959/1968”, Revista Crítica de Ciências Sociais, 91, 2010, pp. 41-57.

${ }^{4}$ Vittorio Gregotti, Il territorio dell'architettura, Milano, Feltrinelli, 1966. 
europeia e sobretudo a da Europa meridional. De facto, e ainda que retomada à escala do equipamento local, essa relação era visivelmente pungente nas primeiras obras de Siza, construídas em diálogo aberto com o Oceano Atlântico.

Para as ver e sentir ao vivo, Gregotti desloca-se ao Porto, em 1971, e ali compreende melhor o universo metodológico que Siza herdara de Fernando Távora, seu professor, empregador e amigo, baseado num cruzamento conceptual entre tradição histórica e modernidade, entre a dimensão universal e a local, entre o conhecimento do território e a sua "domesticação" pela arquitectura. Na verdade, Gregotti identifica ali um método afim daquele legado pelo seu próprio mestre: Ernesto Nathan Rogers, membro do colectivo de arquitectos BBPR e ex-director da revista Casabella. Essa afinidade leva-o pois a escrever, logo em 1972, um importante artigo sobre a sua "descoberta" portuguesa para a revista Controspazio. Afirma então Gregotti sobre Siza, num certo tom psicanalítico:

Alvaro Siza y Vieira è un architetto fuori moda: non dispone di un apparato teorico, non ha mai affrontato grandi temi di sviluppo urbano, parla poco, timidamente, solo il suo cantante portoghese, con parole comuni, a bassa voce. [...] La qualità della rete di tensioni che egli istruisce, precise, commoventi (per usare una parola fuori moda come lui) è fatta, io credo, principalmente di due materiali: l'attenzione e il disagio, la chiara certezza cioè che ciò che è essenziale è sempre un po' spostato rispetto alle direzioni scelte come alle spiegazioni possibili. ${ }^{5}$

Em Siza, como noutros arquitectos da chamada Escola do Porto, Gregotti encontra afinal uma racionalidade inconformada e anacrónica - "fora de moda" como afirma -, talvez mais "poética", mas certamente menos cartesiana, monumental ou literal do que aquela que a cultura arquitectónica italiana experienciava, nesse início da década de 1970, em torno

${ }^{5}$ Vittorio Gregotti, "Architetture recenti di Alvaro Siza”, Controspazio, 9, 1972, pp. 22-25. 
do então denominado Neo-racionalismo, sobretudo no eixo académico Milão-Veneza, no qual ele próprio se movia ${ }^{6}$.

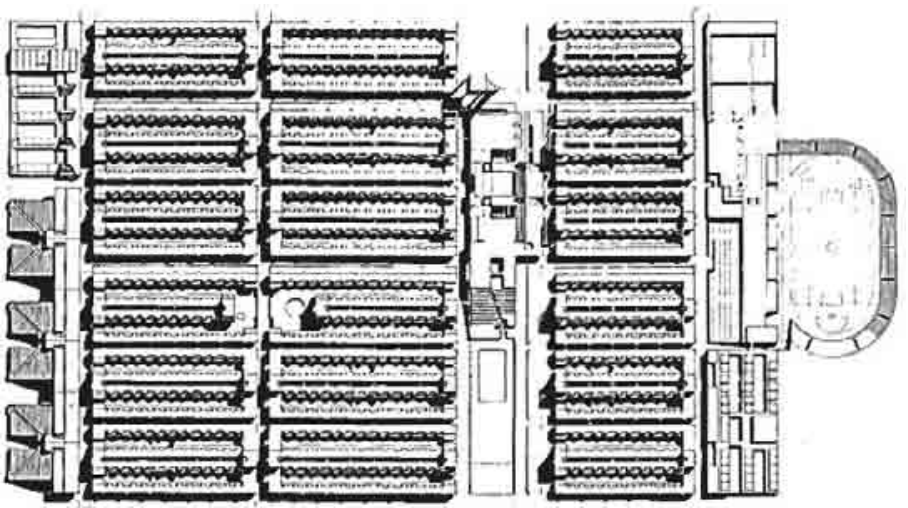

Fig. 2 Vittorio Gregotti, Planta do Bairro ZEN, Palermo, Sicília, 1969.

Fonte: Arquivo Pessoal de Nuno Portas.

SEGUNDA AFINIDADE: UMA POSTURA IDEOLÓGICA SOBRE O HABITAT

A Revolução Portuguesa de 25 de Abril de 1974 trouxe uma nova oportunidade de contacto entre ambos, fortalecida, não apenas pelo entusiasmo gerado por aquele acontecimento político nos meios intelectuais italianos, mas sobretudo pelos novos desafios lançados aos arquitectos para que, onde possível, participassem na construção de alojamento "para o maior numero" de cidadãos portugueses desfavorecidos pelos programas habitacionais iníquos do período ditatorial cessante.

Partilhando uma mesma matriz ideológica, Siza e Gregotti cedo se envolvem, ainda que diferenciadamente, em programas habitacionais lançados durante esse período revolucionário, por alguém que lhes era próximo: Nuno Portas, então

\footnotetext{
${ }^{6}$ Vittorio Gregotti era então Professor de Composição Arquitectónica no Istituto Universitario di Archittetura di Venezia (IUAV), tendo vindo a ser posteriormente professor na Facoltà di Architettura, Politecnico di Milano e na Facoltà di Architettura, Università degli Studi di Palermo.
} 
designado Secretário de Estado da Habitação e Urbanismo do Primeiro Governo Provisório7. Uma vez mais, Portas torna-se fulcral nesse reencontro, convidando-os a debater, em reunióes alargadas a especialistas portugueses e estrangeiros, promovidas no seu Ministério, os diferentes programas que desejava implementar no âmbito do Fundo de Fomento para a Habitação (FFH): o Serviço de Apoio Ambulatório Local (SAAL), as Cooperativas de Habitação Económica (CHE) e os Contratos de Desenvolvimento para a Habitação Social (CDHS).

A participação de Álvaro Siza nesse processo inicia-se no Porto, a partir de um convite das Associações de Moradores e das Brigadas de técnicos do programa SAAL, dos bairros de Nossa Senhora das Dores (São Vítor) e das Águas Férreas (Bouça), duas missões que abraçou com a mesma postura lúcida mas inconformista que colocara na concepção dos seus primeiros projectos. Apesar de interrompidas - após o desmantelamento do Processo SAAL em 1976 -, essas obras marcam decisivamente o seu "salto" profissional para a questão social e para a dimensão urbana, justificando os convites recebidos, no início da década de 1980, para trabalhar em projectos congéneres na Holanda, por requisito do município de Haia, e na Alemanha, no processo de requalificação habitacional de Berlim Ocidental (IBA).

Vittorio Gregotti chega a Lisboa em Maio de 1974, algumas semanas após a Revoluzione dei Garofani (como ficou conhecida em Itália), calcorreando as ruas da cidade, reencontrando calorosamente Álvaro Siza e Nuno Portas, e com eles manifestando-se em prol da Democracia conquistada. A Revolução portuguesa significava, para muitos europeus, um momento de exaltação a favor de uma Europa mais social e cidadã, face aos imperialismos políticos e económicos que marcavam então um mundo em crise, a braços com os impactos do primeiro choque petrolífero de 1973.

7 José António Bandeirinha, O processo SAAL e a arquitectura no 25 de Abril de 1974, Coimbra, Imprensa da Universidade, 2007. 
Gregotti recebe, durante essa visita, uma encomenda voluntarista do Secretário de Estado, Nuno Portas, no sentido de conceber, para o FFH, um Plano Integrado de Habitação Social, na Península de Setúbal, destinado a 12.000 habitantes, e tendo como base o vasto programa de realojamento que, enquanto urbanista e arquitecto, ele mesmo desenvolvia em Palermo, na Sicília, desde 1969, o denominado Quartiere ZEN (Zona Espansione Nord). Reforçando o seu desejo pragmático de ver o processo avançar rapidamente, Portas propõe a Gregotti que a obra fosse acompanhada, em Portugal, por um dos seus ex-alunos de arquitectura na Escola de BelasArtes de Lisboa, então envolvido noutros programas sociais em Setúbal, Manuel Salgado - uma sugestão bem aceite, e que veio cimentar uma nova e duradoura afinidade ${ }^{8}$.

Infelizmente, a exoneração de Nuno Portas do governo, em Março de 1975, deitaria por terra a possibilidade de avançar com o projecto, sendo o Plano Integrado de Setúbal retomado mais tarde, em 1976, já não por Vittorio Gregotti, mas pelo seu conterrâneo Aldo Rossi, em articulação com o arquitecto português José Charters Monteiro, num processo que conduziu à edificação do Bairro Social da Bela Vista, desenhado pelos dois autores naquela cidade.

Durante os anos sequentes, Siza e Gregotti são agastados por críticas recorrentes aos seus projectos de realojamento social, respectivamente: no Porto, face aos bairros de São Vítor e da Bouça, ambos afectados pela interrupção do programa SAAL/Norte, e a partir de então à mercê da ostracização política e mediática; em Palermo, em face da incapacidade do poder público de completar a malha urbana do Bairro ZEN, com espaços verdes e equipamentos públicos desejados pela

\footnotetext{
${ }^{8}$ Informação transmitida oralmente por Manuel Salgado, em conversa pessoal ocorrida em Setembro de 2005 durante o processo de investigação com vista à realização de Prova de Doutoramento. Ver Nuno Grande, Arquitecturas da cultura. Política, debate, espaço. Génese dos grandes equipamentos culturais da contemporaneidade portuguesa, Dissertação de Doutoramento apresentada à Universidade de Coimbra, 2009.
} 
população, sendo esta votada, também aqui, à exclusão política e social.

No entanto, e observando cuidadosamente esses projectos, percebemos que neles existe a mesma vontade de pensar o novo habitat a partir da estrutura, da densidade e da coesão social das cidades onde se integram, e nunca em ruptura com estas. Neles, o desenho das ruas, dos pátios e das galerias comuns promove o encontro cidadão e a equidade colectiva, na relação com o espaço vivencial de cada família, de cada indivíduo. Nesses lugares, adivinha-se uma outra afinidade electiva entre Siza e Gregotti: uma permanente crença na socialização do espaço urbano.

\section{Terceira AFINIDAde: UM FASCÍNIO MÚTUO}

A partir de meados da década de 1970, Vittorio Gregotti e o universo editorial italiano a que estava ligado (sobretudo o Grupo Electa), permanecem atentos às criaçóes de Siza, sendo, em grande parte, responsáveis pela sua rápida internacionalização no seio da cultura arquitectónica europeia, e também pelos convites que lhe são então dirigidos para viajar, expor, debater e construir em solo italiano. Nesse sentido, Siza e a Itália passam a nutrir um definitivo fascínio mútuo.

Depois da referida edição em Controspazio, de 1972, sucedem-se publicações regulares da sua obra noutras importantes revistas italianas: na Lotus International, liderada, desde 1977, por Pier Luigi Nicolin; na Casabella, que Gregotti passa a dirigir em 1982; e na renovada Domus, chefiada, a partir de 1990, por Vittorio Magnago Lampugnani. Pela mão da editora Electa e dos seus Quaderni di Lotus, Siza conhece o primeiro "best-seller" internacional sobre o seu trabalho, publicado em Milão, em 1986: Alvaro Siza. Professione poetica?. $\mathrm{O}$ livro integra textos de alguns dos seus "compagnons de route" dentro e fora de Portugal: Nuno Portas, Alexandre Alves Costa, Oriol Bohigas, Bernard Huet, Kenneth Framp-

\footnotetext{
${ }^{9}$ Pierluigi Nicolin (dir.), Alvaro Siza. Professione poetica, Milano, Electa, 1986.
} 
ton, Pierluigi Nicolin (editor da obra) e naturalmente, do amigo Vittorio Gregotti, que, nessa edição, retoma o seu texto escrito em 1972.

Durante o mesmo período, Gregotti torna-se comissário da primeira incursão pela arquitectura realizada no âmbito da Bienal de Arte de Veneza (1976), organizando uma curiosa exposição-cruzamento entre arquitectos europeus e americanos, nos Magazzini del Sale, em Zattere, colmatada por um debate público com os mesmos intervenientes, no Palácio do Cinema do Lido. O evento, intitulado Europa-América. Centro Storico e Suburbio ${ }^{10}$, coloca em confronto criadores de vários países da Europa, tais como: Oriol Bohigas, Herman Hertzberger, Hans Hollein, Alison e Peter Smithson, Aldo van Eyck, Aldo Rossi e, inevitavelmente, Álvaro Siza; e do lado americano, entre outros, Peter Eisenman, John Hedjuk, Richard Meier, Charles Moore, Robert Stern, Robert Venturi e Denise Scott-Brown.

A partir desse evento, Álvaro Siza inicia um contacto regular com a Itália, traduzido: em novas conferências de apresentação da sua experiência no Processo SAAL (juntamente com Nuno Portas e Alexandre Alves Costa, em $1977^{11}$ ); numa primeira exposição antológica da sua obra no Padiglione d'Arte Contemporanea de Milão, comissariada pelo próprio Vittorio Gregotti $(1979)^{12}$; em projectos para a Sicília, como a reconstrução da Chiesa Madre (1984-1998) e da Piazza Alicia (1991-1998) de Salemi (ambos com Roberto Collovà); e, por fim, na participação em concursos e planos urbanísticos, não realizados, para Caserta (1984), Nápoles (1986), e Siena $(1988)^{13}$.

${ }^{10}$ Vittorio Gregotti (dir.), Europa-America. Centro Storico e Suburbio, Venezia, La Biennale di Venezia, 1976.

${ }^{11}$ Susana Lobo, "Viaggio in Italia. O SAAL Norte e os anos de chumbo", Estudos Italianos em Portugal, n. s., 9, 2014, pp. 27-46.

${ }^{12}$ Vittorio Gregotti (dir.), Alvaro Siza Architetto. 1954-1979, Milano, Idea Editions, 1979.

${ }^{13}$ Roberto Cremascoli; Francesco Moschini, Alvaro Siza in Itália. Il Grand Tour, 1976-2016, Roma, Accademia Nazionale di San Luca, 2016. 
O seu maior triunfo estava guardado, no entanto, e de novo, para Veneza, com a vitória no Concurso para o Plano de Requalificação do Campo di Marte, na ilha da Giudecca, em 1985, cuja implementação se prolonga até hoje. Nesse mesmo ano, Gregotti publicita entusiasticamente a vitória de Siza em Veneza, no n. ${ }^{\circ} 518$ da sua revista Casabella, destacando o modo como o arquitecto português condensava todo o seu fascínio por Itália nesse plano sensível e criterioso para a Serenissima ${ }^{14}$.

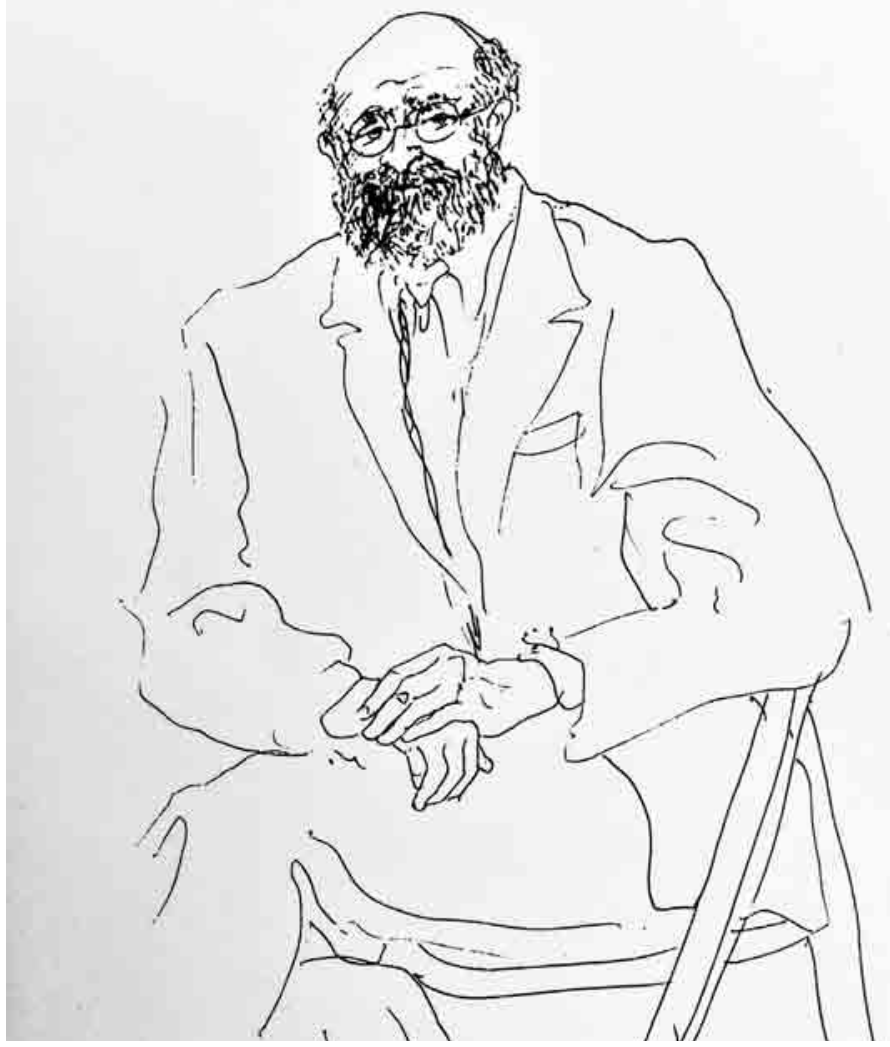

Fig. 3 Álvaro Siza, Retrato de Vittorio Gregotti, 1990. Fonte: Arquivo de Álvaro Siza.

${ }^{14}$ Casabella, 518, 1985, pp. 4-21. 
Em 1990, seria a vez de o atelier Gregotti Associati publicar, na editora Electa, uma retrospectiva das suas obras, nela apresentando quase 300 projectos em áreas tão distintas quanto o planeamento urbano, a arquitectura, o design de equipamento e o design gráfico ${ }^{15}$. A fechar a edição, precisamente na sua última página, Álvaro Siza retribuía a longa amizade, dedicando três retratos a Gregotti, em jeito de esquisso, e um pequeno texto. Nele, e em sentido inverso, Siza devolvia-lhe, quase 20 anos depois, a sua primeira análise, e num mesmo tom psicanalítico:

Non riesco a disegnare un ritratto preciso. Solo un momento, e un altro momento, durante il lavoro di gruppo. Vittorio apprende le cose e progetta - con la rapidità di un lampo. Poi aspetta, il corpo inclinato, leggermente divertito, leggermente irritato per il ritardo. Cézanne. Solleva il calcagno di uno dei piedi, mentre l'altro poggia come la base di un pilastro. La gamba vibra in oscillazioni verticali molto rapide, di ritmo costante, come la biella di una locomotiva. Il pavimento geme, ogni tanto si sente un tintinnio di bicchieri troppo vicini.

Aspettiamo di tutto, un terremoto o un batter d'ali. Arriviamo finalmente a una conclusione. Si alza, due dita nell'aria, un sorriso di sollievo. ${ }^{16}$

$\mathrm{Na}$ mesma edição, Gregotti publica um concurso, ganho pelo seu atelier em 1988, para o novo Centro Cultural de Belém, um extenso edifício na frente ribeirinha da capital portuguesa, no qual vinha trabalhando com afinco e entusiasmo. De algum modo, se Siza consolidava as suas afinidades italianas no seu Plano para Veneza, Gregotti reencontrava as suas afinidades portuguesas nessa nova proposta para Lisboa.

${ }^{15}$ Paolo Colao; Giovanni Vragnaz (dir.), Gregotti Associati. 1973-1988, Milano, Electa, 1990.

${ }^{16}$ Álvaro Siza, "Vittorio", in Paolo Colao; Giovanni Vragnaz (dir.), cit., p. 339. 


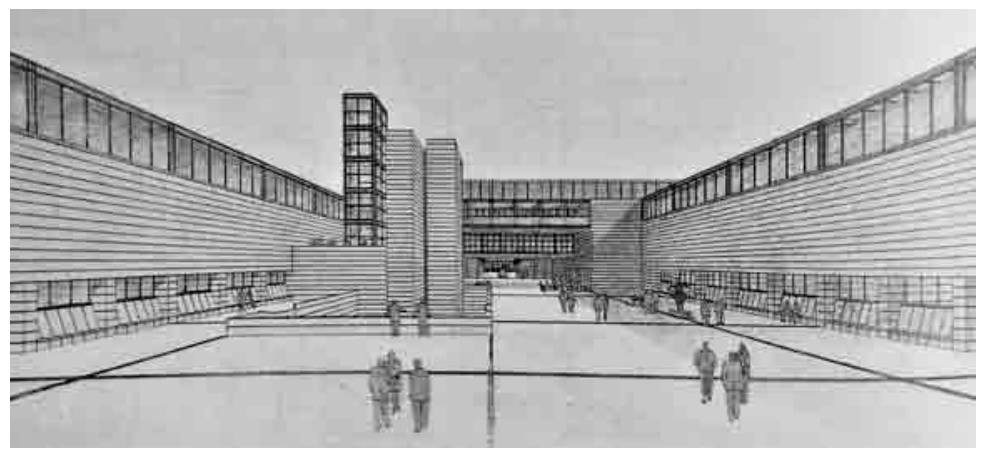

Fig. 4 Vittorio Gregotti e Manuel Salgado, Perspectiva do Projecto para o Centro Cultural de Belém. Fonte: Arquivo da Fundação Centro Cultural de Belém.

QUARTA AFINIDADE:

LISBOA COMO LABORATÓRIO URBANO PARTILHADO

O ano de 1988 constitui, como veremos, um momento marcante nas vidas de Álvaro Siza e de Vittorio Gregotti. A 25 de Agosto, um fatídico incêndio eclode no Bairro do Chiado lisboeta, após o qual, e numa polémica decisão política, o Presidente do Município, Nuno Abecassis, encomenda directamente a Siza um Plano de Reconstrução para toda a zona sinistrada; a 17 de Dezembro, o júri do Concurso Internacional para o Centro Cultural de Belém (CCB) anuncia que a sua escolha recai na proposta apresentada pelo atelier Gregotti Associati em sociedade com o atelier português Risco.

A partir de então, e embora enfrentando problemáticas distintas, os dois arquitectos debruçam-se sobre Lisboa enquanto "cidade-palimpsesto"; isto é, formada por diferentes sedimentos históricos, que ambos estudam e integram "laboratorialmente" no novo estrato arquitectónico acrescentado pelo seu projecto. Siza e Gregotti trabalham, enfim, a partir de um método "historicista", mas onde o passado se torna num instrumento operativo do presente e do futuro da cidade. Vejamos como se cruzam as suas visões sobre Lisboa. 
Revisitando criticamente a grande empreitada da reconstrução lançada pelo Marquês de Pombal após o Terremoto de 1755, entre a Baixa e o Chiado, Álvaro Siza repõe ou resgata a métrica urbana e arquitectónica desenhada pelos engenheiros militares pombalinos, cruzando-a com a opção de amenizar a densidade construtiva no seio dos quarteirôes e dos lotes desse extenso e compacto bairro. Do seu Plano de Reconstrução, renasce um tecido urbano racional, onde a matriz histórica se revela, na relação entre tipologia e morfologia, na austeridade das fachadas reconstruídas e nos métodos estandardizados de construção, lado-a-lado com um inovador e radical gesto contemporâneo, no modo como os interiores dos quarteirões do Chiado se abrem à restante cidade e se democratizam no seu uso fluido, colectivo e cosmopolita ${ }^{17}$.

A proposta de Vittorio Gregotti para o novo CCB, assinada conjuntamente com Manuel Salgado (RISCO), marca não só o reencontro entre esses dois arquitectos - após o seu primeiro cruzamento em Lisboa, no período revolucionário - como resulta, de novo, do desejo de Nuno Portas de ver o seu colega italiano debater e pensar a urbanidade portuguesa ${ }^{18}$. Na verdade, e obedecendo a uma prerrogativa do júri do Concurso Internacional para o CCB (que Portas integrou como representante da Associação dos Arquitectos Portugueses ${ }^{19}$ ), diversos convites directos foram realizados a personalidades nacionais e estrangeiras para que se apresentassem à consulta pública da, até então, maior obra arqui-

${ }^{17}$ Bernard Colenbrander (dir), Alvaro Siza. The Strategy of Memory, Chiado, Lisbon, Rotterdam, NAI Publishers, 1991.

${ }^{18}$ Informação transmitida oralmente por Manuel Salgado, em conversa pessoal ocorrida em Setembro de 2005 durante o processo de investigação com vista à realização de Prova de Doutoramento. Ver Nuno Grande, cit.

${ }^{19}$ Para além de Nuno Portas, o júri integrava o presidente António Lamas, pelo Instituto Português do Património Cultural, sendo os restantes vogais: Manuel da Costa Lobo, responsável pelo Plano de Salvaguarda e Valorização de Belém/Ajuda, Charles Delfante, da Associação Internacional de Urbanistas; Frederico George, da Academia Nacional de Belas-Artes; e os especialistas convidados, Fernando Távora, Pierluigi Nicolin e Leslie Martin. Ver Nuno Grande, "Grands Travaux em Belém”, in Arquitectura em concurso (dir. Luís Santiago Baptista), Porto, Dafne, 2016, pp. 82-93. 
tectónica construída no período democrático em Portugal $^{20}$. Na perspectiva de Portas, esta era também a oportunidade de Gregotti sedimentar a sua longa proximidade com a cultura portuguesa, sobretudo num momento em que o país iniciava a integração na Comunidade Económica Europeia (CEE).

O programa para o novo CCB previa duas componentes fundamentais: uma lúdico-cultural (cruzando um módulo de Centro de Espectáculos com um módulo de Centro de Arte) e uma político-empresarial (juntando um módulo de Centro de Conferências e Reuniōes governamentais, com um módulo de Serviços e Hotel). Sendo que, no seu conjunto, as duas componentes deveriam ser construídas, em tempo recorde, para receber a primeira Presidência Portuguesa da CEE, em 1992.

Manuel Salgado relata que Vittorio Gregotti aterra em Lisboa, em Abril de 1988, três meses após o lançamento do concurso internacional, trazendo em mãos o seu cartão de embarque totalmente desenhado, e nele contendo, já esquematizados, os cinco módulos da proposta ${ }^{21}$. Gregotti fazia, de facto, jus à sua filiação neo-racionalista, estabelecendo, desde logo, uma trama de composição, para todos os módulos, a partir de múltiplos e submúltiplos de 7,5 metros. $\mathrm{Na}$ verdade, o arquitecto italiano, mais não fazia do que evocar uma estratégia ancestral da romanização - sempre presente no seu trabalho -, baseada numa espécie de "centuriação" territorial, desta vez adaptada, de forma pragmática e inteligente, à frente ribeirinha de Lisboa.

Essa estratégia teve de se confrontar, no entanto, com os diversos sedimentos geográficos e históricos que caracterizam

${ }^{20}$ Informação transmitida oralmente por António Lamas, Presidente do Júri do Concurso para o Projecto do Centro Cultural de Belém, em conversa pessoal ocorrida em Dezembro de 2005, durante o processo de investigação com vista à realização de Prova de Doutoramento. Ver Nuno Grande, Arquitecturas da cultura [...].

${ }^{21}$ Informação transmitida oralmente por Manuel Salgado, em conversa pessoal ocorrida em Setembro de 2005 durante o processo de investigação com vista à realização de Prova de Doutoramento. Ver Nuno Grande, Arquitecturas da cultura [...]. 
a zona de Belém: o Rio Tejo, as antigas estruturas militares e portuárias de defesa e domínio das suas margens, os monumentos simbólicos como a Torre de Belém e o Mosteiro dos Jerónimos, e os fragmentos urbanos legados pela Exposição do Mundo Português, realizada naquele local, em 1940. Nesse sentido, para Gregotti, o novo CCB constituía muito mais do que um programa arquitectónico, sendo uma oportunidade única de urdir um tecido urbano que cosesse e integrasse todas essas memórias e fragmentos, numa solução coesa isto é, numa espécie de "micro-cidade". Desta, como se sabe, apenas estão construídos três dos cinco módulos desenhados por Gregotti e Salgado, faltando ainda hoje concluir, no seu topo poente, as componentes de Serviços, Comércio e Hotel requeridas pelo programa.

No entanto, e observando o conjunto edificado e inaugurado em 1992 - os módulos para Reuniōes/Congressos, para Espectáculos e para Centro de Arte -, percebemos como Gregotti revisita, com um olhar contemporâneo, esse legado histórico que caracteriza a relação ancestral de Lisboa com o Tejo. O Centro Cultural de Belém reúne, na sua coerência volumétrica, o imaginário das fortalezas, dos palácios e dos conventos ribeirinhos, mas também a densa malha de quarteirões e de ruas do período pombalino, que emolduram o rio, gerando, no seu conjunto, uma sucessão de eixos, praças e jardins suspensos, os quais nos remetem para a alternância de abertura e de recolhimento paisagístico que sentimos quando deambulamos pelo centro histórico lisboeta.

Essas foram características valorizadas pelo júri, entre as 53 propostas apresentadas no concurso internacional, realizado em duas fases ${ }^{22}$, e que deu lugar, em Portugal, a um inte-

${ }^{22} \mathrm{O}$ concurso teve duas fases: a primeira com entrega de trabalhos anónimos de onde resultaram seis finalistas, para uma segunda fase, já sem anonimato. Os seis finalistas foram: Jean Tribel; Jean Pistre (Valode \& Pistre); Renzo Piano (Building Workshop), Vittorio Gregotti/Manuel Salgado (Gregotti Associati/Risco), Manuel Tainha e Gonçalo Byrne. Ver Nuno Grande, "Grands Travaux em Belém”. 
ressante confronto entre as diversas posições que marcavam então o aceso debate pós-moderno em torno da revisita e do reuso da História em Arquitectura. Por conseguinte, na transição para a década de 1990, Chiado e Belém são palcos de dois projectos exemplares desse pertinente debate, sendo respectivamente coordenados por dois arquitectos que transportam um profundo conhecimento da cultura urbana europeia de matriz latina.

Passaram mais de 25 anos sobre o Plano de Reconstrução do Chiado de Álvaro Siza, e sobre o Projecto do CCB, gizado por Vittorio Gregotti. Ao longo desse período, a capital portuguesa vem sendo sujeita a progressivas pressóes urbanísticas legadas pelo investimento imobiliário, pelo turismo e pela gentrificação social e cultural. Chiado e Belém são hoje lugares muito distintos do que eram nesse ano marcante de 1988. E isso deve-se, em grande parte, à releitura que Siza e Gregotti desenvolveram sobre a Lisboa Iluminista, dela resgatando um desenho para a cidade, baseado, democraticamente, na valorização da cidadania.

\section{Afinidades RECENTES: REENCONTROS EM LisboA E VeneZA}

Em 2007, com 80 anos, Vittorio Gregotti recebe o Prémio Carreira da 1. a Trienal de Arquitectura de Lisboa. Álvaro Siza, convidado a ser o patrono do prémio, confessaria durante a cerimónia, dedicada ao seu amigo italiano:

Comecei por recusar este desígnio, sem sucesso. Até que, quase por instinto, surgiu no meu espírito um nome: Vittorio Gregotti, membro da brilhante geração de arquitectos italianos que iniciou a prática profissional nos anos 50 e que se tornou amigo de Portugal desde os anos 60. (...) Gregotti, que sempre recusou o brilho imediato, e por isso muitas vezes fugaz, participou de forma decisiva na transformação do nosso país. ${ }^{23}$

\footnotetext{
${ }^{23}$ Álvaro Siza citado pela jornalista Alexandra Prado Coelho, Público, 28-07-2007.
} 
Quase uma década depois, a obra de Habitação Social de Álvaro Siza é escolhida como tema do pavilhão de Portugal na Bienal de Arquitectura de Veneza de 2016, ano em que também o Museu Nacional de Arte do Século XXI (MAX$\mathrm{XI}$ ), em Roma, organiza uma retrospectiva em torno da sua relação com o Sagrado: Alvaro Siza Sacro ${ }^{24}$. Durante a Bienal, Siza e Gregotti reencontram-se, uma vez mais, em Veneza, e relembram, 40 anos depois, a primeira edição do evento dedicada à arquitectura, organizada pelo italiano, e que incluía, como descrevemos, a primeira exposição internacional do português.

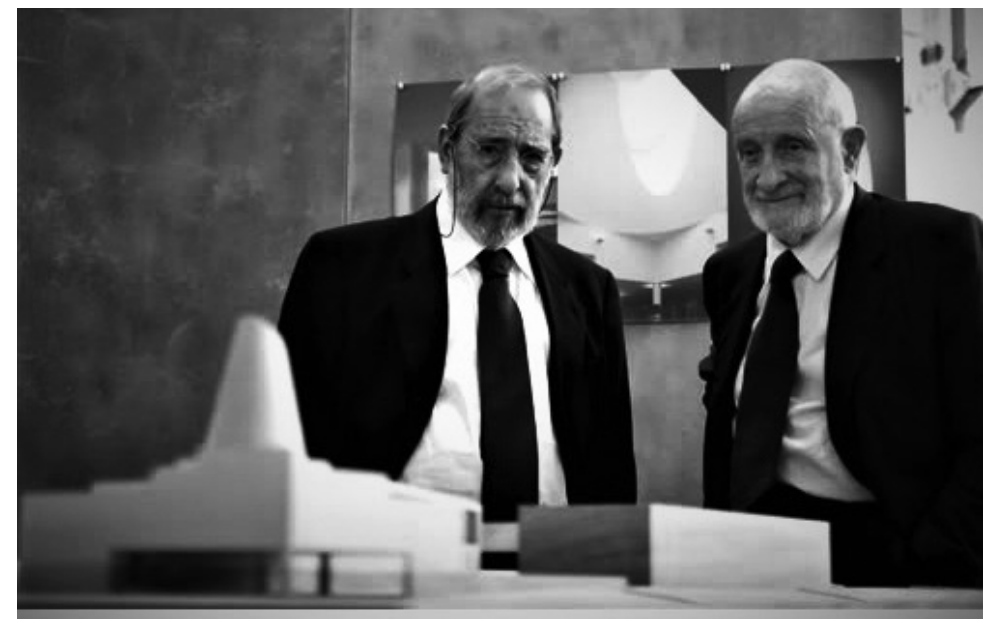

Fig. 5 Álvaro Siza e Vittorio Gregotti em Lisboa, 2007. Fonte: Arquivo da Trienal de Arquitectura de Lisboa.

Ainda em 2016, com 83 anos, Siza inaugura a sua maior obra pública em solo italiano, assinada com Eduardo Souto de Moura: a estação de Metro Municipio em Nápoles, de novo um exercício de releitura crítica da estratificação histó-

${ }^{24}$ A exposição Siza. Sacro teve curadoria de Achille Bonito Oliva e Margherita Guccione, com a direcção científica de Roberto Cremascoli (MAXXI, Roma, 09-11-2016 a 26-03-2017). 
rica da cidade. Por toda a Itália sucedem-se, então, convites para obras, exposiçóes, entrevistas e palestras, que consolidam o fascínio daquela cultura arquitectónica pela figura e pela obra de Siza.

No entanto, nada terá sido mais significativo para Siza do que o texto inédito que Gregotti enviou à Cerimónia de Encerramento do Pavilhão de Portugal na Bienal de Veneza desse ano, reafirmando a admiração pessoal pelo seu amigo português. Na missiva, Gregotti revisitaria esses 40 anos de afinidade, escrevendo:

[...] Al di là delle non secondarie ragioni di profonda amicizia personale, ciò che ha consolidato il nostro rapporto nel tempo è certamente la comunanza dei nostri punti di vista intorno al progetto di architettura come ricerca di un frammento di verità del presente e di un suo senso possibile e necessario, ed anche proprio la presa di coscienza di far parte di una minoranza che si riconosce in una critica positiva, ma non praticistica né formalista, degli ideali della tradizione del movimento moderno.

Proprio a partire da una quarantina di anni fa abbiamo cominciato a discutere insieme con lui intorno all'idea della creatività in architettura come modificazione cioè come riconoscimento dialetticamente inteso del contesto fisico, e della storia delle culture come terreno di fondazione di ogni architettura, un terreno che ci lascia liberi e responsabili intorno alla direzione da prendere con il nostro specifico progetto.

[...] L'architettura di Siza è progetto di dialogo critico con la realtà, costruzione cioè di una distanza appassionata che è lo spazio in cui si costituisce la qualità della migliore architettura del nostro tempo. Nel primo testo da me scritto sul suo lavoro nel 1972 avevo affermato che Alvaro Siza non aveva mai affrontato grandi temi di sviluppo urbanistico, parlava poco, timidamente, il suo cantante portoghese, con parole comuni, a bassa voce anche se si sentiva, come ogni architetto, politicamente impegnato, Siza non ha venerazioni tecnologiche o monumentali, ama le piccole cose, i segni sottili. Tutti modi di essere 
della sua passione paziente, profonda, piena di trepidazione verso l'architettura che anche oggi lo caratterizza: egli ne ha trovato un punto certamente interno alla poesia del progetto di architettura ed ora accerta, con le mani, le qualità dei suoi margini. ${ }^{25}$

Cremos que será difícil encontrar, na criação arquitectónica contemporânea, um texto pessoal que melhor traduza essa dimensão íntima, ideológica e ética da amizade, capaz de transformar uma natural proximidade cultural numa verdadeira "afinidade electiva".

${ }^{25}$ O texto inédito de Vittorio Gregotti foi enviado a Álvaro Siza por ocasião do Programa de Encerramento do Pavilhão de Portugal na XV Bienal de Arquitectura de Veneza de 2016 (Aula Magna da Università IUAV di Venezia, 25-11-2016). 